\title{
IMAGEM E BIOPODER: UM ESTUDO DOS PROCESSOS DE SUBJETIVAÇÃO IMPLICADOS NAS DINÂMICAS DO INSTAGRAM
}

Image and biopower: a study upon subjectivation process embodied in Instagram use

Fabíola Stolf Brzozowski

Doutora em Saúde Coletiva pela Universidade Federal de Santa Catarina,

Florianópolis, Brasil

fabiola.stolf@gmail.com

https://orcid.org/0000-0002-8697-2120 (1)

\author{
Mauricio José Melim \\ Doutorando do Programa de Pós-Graduação \\ Interdisciplinar em Ciências Humanas \\ da Universidade Federal de Santa Catarina, \\ Florianópolis, SC, Brasil \\ mauriciomelim@gmail.com \\ http://orcid.org/0000-0002-1111-1625 (D)
}

\section{RESUMO}

A lista completa com informações dos autores está no final do artigo

Este trabalho faz uma análise das dinâmicas da plataforma de fotos e vídeos Instagram, uma das mais populares atualmente. Argumenta-se que a autoexposição e a "vigilância" do outro incentivadas pela rede social contribuem para a produção de um tipo de subjetividade afim ao funcionamento do biopoder contemporâneo. Sob o biopoder, seres humanos tendem a pensar-se como seres individuais, livres e capazes de autogoverno. Para compreender como o Instagram participa desse processo de subjetivação, aplicou-se um modelo teórico que discute as dinâmicas da plataforma considerando um conjunto de dimensões-etapas. Esse procedimento demonstra de que maneira ações como expor-se e ver os outros, avaliar e ser avaliado podem engendrar sujeitos que creem serem livres, mas que ao mesmo tempo estão preocupados com sua performance na rede e fora dela. Este estudo espera colaborar para a compreensão dos modos pelos quais os poderes estão atuando e governando seres humanos na atualidade.

PALAVRAS-CHAVE: Instagram. Imagem. Subjetividade. Biopoder. Redes Sociais.

\begin{abstract}
This article analyzes the dynamics of the Instagram photo and video platform, one of the most popular today. It argues that the self-exposure and "surveillance" of the other encouraged by the social network contribute to the production of a type of subjectivity related to the functioning of contemporary biopower. Under biopower, human beings tend to think of themselves as individual beings, free and capable of self-government. To understand how Instagram participates in this process of subjectification, a theoretical model was applied that discusses the dynamics of the platform considering a set of dimensions-steps. This procedure demonstrates how actions such as exposing oneself and seeing others, evaluating and being evaluated can generate subjects who believe they are free, but who at the same time are concerned with their performance on the network and outside it. This study hopes to collaborate to understand the ways in which the powers are acting and governing human beings today.
\end{abstract}

KEYWORDS: Instagram. Image. Subjectivity. Biopower. Social Networks.

\section{INTRODUÇÃO}

As formas de exercício do poder vêm sofrendo importantes mudanças nas últimas décadas. Em regimes militares, como as ditaduras sul-americanas, por exemplo, o poder agia por meio da coerção e era facilmente identificável. Hoje, tais características já não 
condizem com sua realidade. O poder tem-se convertido em um gesto estimulante, dirigido cada vez mais à subjetividade e de identidade ambígua e difusa. O poder se encontra emaranhado nas atividades mais cotidianas e ordinárias (PELBART, 2007), como é o caso das redes sociais.

Neste trabalho, parte-se do princípio de que o Instagram, a rede online de compartilhamento de imagens e vídeos, constitui uma das expressões do poder contemporâneo. Pela hipótese assumida, as dinâmicas visuais que se desenvolvem na plataforma podem atuar sobre a subjetividade de seus usuários de forma a exercer sobre eles um tipo de regulação. O que se pretende analisar é a maneira pela qual esse processo ocorre.

As imagens do Instagram parecem particularmente aptas a intensificar a subjetividade na medida em que incentivam usuários a documentar suas vidas e a acompanhar a vida dos outros (LASÉN; PUENTE, 2016). Os recursos da plataforma estimulam os usuários a analisar-se e a julgar-se tomando por referência as imagens de outros usuários. Esse processo pode repercutir sobre a subjetividade e, portanto, modificar o sujeito em sua relação consigo e com os outros.

Para pensar a atuação das imagens sobre a subjetividade, tomou-se de empréstimo um modelo teórico elaborado pelo filósofo e pedagogo Jorge Larrosa (2011). O modelo, de bases foucaultianas, surge no contexto escolar, mas sua generalidade, como se verá, permite aplicação a outras áreas. O objetivo do modelo é tornar visível a maneira como as atividades escolares repercutem sobre a subjetividade dos envolvidos, integrando-se a eles e transformando-os. Sua aplicação implica decompor a atividade escolar em cinco dimensões-etapas (nomeadas ver-se, expressar-se, narrar-se, julgar-se e dominar-se) e discutir como cada uma delas pode agir sobre a subjetividade do estudante.

Essa mesma lógica é utilizada aqui para desenvolver uma análise das dinâmicas mais típicas da rede social Instagram, que incluem expor-se e deixar-se avaliar pelos demais usuários, "vigiar" os membros da rede e avaliá-los.

\section{INSTAGRAM}

Nos últimos anos, houve um crescimento significativo da quantidade de imagens digitais. Entre os fatores responsáveis por esse aumento estão: a incorporação de câmeras aos smartphones; a ampliação do acesso à internet bem como da qualidade da transmissão 
de dados; a expansão das redes sociais. A esses poder-se-ia somar ainda o fato de o aparelho estar sempre com o usuário e, portanto, sempre pronto a registrar aspectos de seu cotidiano, seja algo extraordinário ou completamente banal. Tudo isso repercute sobre a relação que se estabelece com a imagem, que tende a ser cada vez mais banalizada. Não havendo excepcionalidade no acontecimento que se registra, não há também grande preocupação com a preservação, o que torna a imagem transitória ou até mesmo descartável (STURKEN, 2017).

"Aproximamos você das pessoas e coisas que ama". Esse é o lema do Instagram, a plataforma de compartilhamento de fotos e vídeos criada por Kevin Systrom e Mike Krieger em 2010 e comprada pelo Facebook em 2012. Contando com mais de um bilhão de usuários ativos mensalmente (INSTAGRAM, 2019), o Instagram é hoje uma das redes sociais mais populares. Diariamente, são publicadas mais de 100 milhões de fotos e vídeos (ASLAM, 2020) e quem publica a maior parte dessas imagens é o usuário comum, anônimo (MANOVICH, 2016). De acordo com Sheldon e Bryant (2016), os usuários utilizam a rede para, antes de mais nada, vigiar ou saber da vida dos outros. Em segundo lugar, para documentar e compartilhar as próprias experiências, fazendo da plataforma uma espécie de álbum. Na terceira posição, está o desejo de cultivar uma imagem legal (cool) para amigos e demais usuários. E, por fim, na quarta posição, os usuários do Instagram afirmam usar a rede para expor suas habilidades criativas e encontrar pessoas com interesses comuns.

A imagem mais frequente é a aquela que visa a documentar algo da vida ordinária do usuário (MANOVICH, 2016). São selfies, imagens com amigos, refeições, festas, animais, objetos, roupas. A prioridade dessas imagens não é "estética": a maior parte delas não demonstra domínio sobre fatores convencionais da "boa fotografia", como contraste, composição, ritmo. Em geral, o que mais importa aos usuários do Instagram é manter o contato com o outro, e isso não significa necessariamente uma busca persistente por curtidas e seguidores.

Há alguns anos, Hu, Manikonda e Kambhampati (2014) fizeram um levantamento em busca de uma tipologia geral das imagens do Instagram e concluíram o seguinte. Selfies e imagens com amigos são a grande maioria. Em seguida, vem as imagens com todo tipo de atividades (indoor e outdoor). Em uma posição intermediária, estão as imagens de alimentos, gadgets e as imagens-com-texto (caso dos memes). Por fim, com uma menor representatividade vem as imagens de pets e moda/vestuário. 
O modo como a plataforma é utilizada sugere um vínculo relativamente forte com a vida subjetiva de seus usuários. A predominância de selfies e de imagens com amigos, 0 desejo de acompanhar a vida do outro e de expor a si mesmo de maneira "cool" são fatos que denotam uma preocupação com o "eu" que cada um está produzindo. Esse processo sugere que os usuários estão construindo um tipo de conhecimento acerca de si mesmos através do Instagram.

\section{BIOPODER E SUBJETIVIDADE}

Neste tópico, serão discutidas e delineadas as noções de biopoder e subjetividade. Essas noções formam uma espécie de par, uma nutrindo a outra: o biopoder precisa de indivíduos de subjetividade densa para funcionar e por isso incita cada qual a cultivar-se como indivíduo, como ser livre que escolhe seus próprios rumos (ROSE, 2011).

O temo biopoder se popularizou com Foucault (2011) e refere-se ao poder sobre a vida, que se inaugura a partir do século XVII, por meio de duas formas interligadas. A primeira está relacionada ao adestramento do corpo, para que funcione como uma máquina, aperfeiçoando-o e docilizando-o, por meio das disciplinas, a anátomo-política do corpo humano. A segunda se formou um pouco mais tarde, no século XVIII, e se preocupa com os processos biológicos (nascimento, morbidade, mortalidade, longevidade etc.), ou seja, com a mecânica do ser vivo no corpo-espécie.

Biopoder é uma forma de governo que se caracteriza pela condução da conduta através da intervenção, mais ou menos racionalizada, sobre aspectos vitais da existência humana (ROSE, 2011). Em tempos passados, reis e Estados exploraram ao máximo a força dos corpos, abandonando-os quando esgotados. O biopoder se distingue porque se preocupa com a preservação da vida e, mais que isso, com a administração da vida, tendo sempre por horizonte a produtividade. Foucault (2011, p. 153) afirma que o biopoder foi chave para o desenvolvimento do capitalismo, "[...] que só pôde ser garantido à custa da inserção controlada dos corpos no aparelho de produção e por meio de um ajustamento dos fenômenos de população aos processos econômicos." Se, em uma primeira etapa, o biopoder se ocupou de aspectos mais biológicos, hoje dirige-se também, e cada vez mais, para a administração da psique (HAN, 2014; ROSE, 2011).

De acordo com Han (2014), as feições adquiridas pelo poder têm a ver com o sistema produtivo em vigência. Assim, de uma sociedade agrária passou-se a uma sociedade 
industrial, e desta a uma sociedade da informação. Se nas sociedades agrárias o poder explorava a força física dos trabalhadores, agora é preciso administrar sua energia psíquica. Nas sociedades da informação, o poder incentiva e cobra dos indivíduos o cultivo intelectual: manter-se bem-informado, desenvolver a criatividade. E esse mesmo poder exige que se cultive ideias como liberdade, autonomia e responsabilidade (PELBART, 2007; HAN, 2014).

Na citação a seguir, Pelbart oferece um conjunto de traços acerca do biopoder. Chama a atenção para o fato de não se tratar de um poder externo e superior, mas interno e, por isso mesmo, difícil de identificar. Esse poder, diz o autor,

[...] já não se exerce desde fora, desde cima, mas sim como que por dentro, ele pilota nossa vitalidade social de cabo a rabo. Já não estamos às voltas com um poder transcendente, ou mesmo com um poder apenas repressivo, trata-se de um poder imanente, trata-se de um poder produtivo. Este poder sobre a vida [...] não visa mais, como era o caso das modalidades anteriores de poder, barrar a vida, mas visa encarregar-se da vida, visa mesmo intensificar a vida, otimizá-la. Daí também nossa extrema dificuldade em resistir. Já mal sabemos onde está o poder e onde estamos nós. O que ele nos dita e o que nós dele queremos. Nós próprios nos encarregamos de administrar nosso controle, e o próprio desejo já se vê inteiramente capturado. Nunca o poder chegou tão longe e tão fundo no cerne da subjetividade e da própria vida, como nessa modalidade contemporânea do biopoder (PELBART, 2007, p. 58).

O biopoder é difícil de ser localizado, pois está espraiado na vida social em agentes e instituições como a ciência, o capital, a mídia, além do próprio Estado (PELBART, 2007). Sua lógica de atuação é a lógica da informação e da persuasão. Não se trata, então, de impor uma determinada ideia ou um dado comportamento, mas de criar as condições para que o indivíduo adira "por si mesmo" a essa ideia ou comportamento. É assim que a noção de autonomia pessoal, reprimida no passado, torna-se uma peça estratégica. Como notou Rose:

Nós agora podemos ser governados pelas escolhas que nós mesmos fazemos, sob a condução das autoridades cognitivas e culturais, no espaço da liberdade regulada, na nossa busca individual pela felicidade, autoestima e autorrealização, para a satisfação de nossos selfs autônomos (ROSE, 2011, p. 231).

Essa lógica de atuação depende, por sua vez, de mecanismos de representação da realidade, mecanismos capazes de tornar a realidade inteligível e, assim, calculável e administrável (ROSE, 2011). Deste modo, a título de ilustração, desde meados do século XX diversos estudos de psicologia vêm sendo aplicados ao universo do marketing e do consumo. São estudos que visam a entender como ocorre a compra, quais as motivações, 
o que funciona e o que não funciona em termos de argumentos publicitários. Para isso, constroem uma gama de métricas, de esquemas descritivos, de explicações e conceitos. $\mathrm{Na}$ base desses estudos, está o desejo de pôr em sintonia anunciantes e público-alvo.

É importante perceber nesse processo a interdependência entre os mecanismos de representação, com sua linguagem e seus conceitos, e aquilo que é chamado, em sentido lato, de realidade. $O$ aspecto importante é que esses mecanismos de representação não são meramente "descritores" da realidade. Eles são também criadores. Não se trata de um simples processo de nomeação de algo preexistente e pré-formatado, e sim de uma realidade que emerge porque, em um dado momento, inventou-se um vocabulário que a torna cognoscível (ROSE, 2011; LARROSA, 2011).

É dentro dessa perspectiva que aqui se está pensando a relação entre biopoder e subjetividade. Os mecanismos do biopoder tendem a produzir um tipo de subjetividade densa, inflada, na medida em que interpelam seres humanos como indivíduos, como seres racionais e autoconscientes, que devem buscar "a verdade" em seu "interior". Essa subjetividade ganha contornos e concretude, e se torna uma "realidade", porque começa a participar da conversação cotidiana. Isto é, aparece na mídia e na publicidade, nos discursos sobre relacionamento afetivo e empreendedorismo, sobre saúde física e mental, enfim, está na vida social como um todo (ROSE, 2011; HAN, 2014).

Afinal, o que se entende por subjetividade? No senso comum, parece prevalecer a noção cunhada pela filosofia moderna e as ideias liberais. Subjetividade, nesse caso, corresponde a alma, espírito, núcleo, essência ou substância humana, tendo como fronteiras o corpo humano. É a instância que faz do indivíduo um ser racional, consciente de seus pensamentos e de suas ações, um ser responsável por suas escolhas e por seus atos (ROSE, 2011).

Embora isso possa soar natural e óbvio quando se pensa em seres humanos, não há nada de natural nem de óbvio. Essa maneira de pensar a subjetividade, e até mesmo a necessidade de imaginar uma instância com essas qualidades, é fruto de uma história particular, de condições particulares e relativamente deliberadas. Seres humanos tendem a assumir modos de ser inscritos ou veiculados em práticas e discursos cotidianos. Se cada vez mais as pessoas descrevem a si mesmas como indivíduos racionais, livres e autoconscientes é porque na vida doméstica, no trabalho, nos meios de comunicação, no sistema legal, na medicina, enfim, em todos os campos eles são interpelados e condicionados a pensar e a se comportar dessa maneira (ROSE, 2011).

A noção de subjetividade considerada neste estudo difere muito da versão proposta 
pelos modernos. Com Pelbart (2007) e Rose (2011), defende-se que a subjetividade é algo muito mais amplo, instável e, por isso mesmo, complexo de definir. Subjetividade não é um fato da natureza, e sim o produto de uma história. Não é o ponto de partida, como se fosse a substância ou a essência do humano, mas uma espécie de "estação", um ponto de passagem. Além da transitividade, um outro aspecto fundamental da subjetividade é seu caráter composicional. A subjetividade não é, como disseram os modernos, algo alojado dentro de um corpo e, mais importante, não se trata apenas de um conteúdo que sofre mudanças com o passar do tempo. A subjetividade, diz Rose (2011, p. 252), compõe-se e se conecta com "[...] corpos, vocabulários, julgamentos, técnicas, inscrições, práticas." Ou seja, o humano se espalha e é afetado por aquilo que vai além dos limites do corpo. Conforme Rose:

[...] podemos produzir mais em termos de inteligibilidade se consideramos a questão da subjetivação menos em termos de que tipo de sujeito é produzido - um self, um indivíduo, um agente - e mais em termos daquilo que os seres humanos são capacitados a fazer através das formas em que são maquinados ou agenciados. Aquilo que os humanos são capazes de fazer não é intrínseco à carne, ao corpo, à psique, à mente ou à alma: está constantemente se movendo e mudando de lugar para lugar, de época para época, com a ligação de seres humanos a aparatos de pensamento e ação [...] (ROSE, 2011, p. 252).

Essa perspectiva borra as fronteiras que distinguem o dentro e o fora, o central e o marginal. Abala o antropocentrismo já que retira o corpo de sua posição privilegiada. Perdese assim precisão e clareza quanto à "coisa humana", mas ganha-se em inteligibilidade quanto ao que pode o humano a partir das conexões que vivencia. Tais aspectos colidem com a filosofia moderna que descreve o sujeito como um ser unificado, bem localizado e estável. Para os modernos, o sujeito é também racional e tem consciência do que se passa consigo, ele é senhor de si. Justamente por isso é considerado responsável pelos seus atos. Não se pode negar que o humano é capaz de exercer algum controle racional sobre seus pensamentos e ações, e que pode ser responsabilizado por parte do que the ocorre. No entanto, é difícil sustentar, depois do que propuseram a psicanálise, o estruturalismo e o pós-estruturalismo, que existam consciência e controle plenos. A perspectiva adotada aqui entende que afetos e atos não-conscientes são aspectos, no mínimo, tão importantes da vida subjetiva quanto a razão e a consciência.

\section{UM MODELO TEÓRICO PARA PENSAR O INSTAGRAM}


Neste tópico, serão apresentadas as linhas gerais do modelo utilizado para analisar os processos de subjetivação implicados nas práticas de postagem e visualização de imagens no Instagram. A análise será feita no tópico seguinte. O modelo foi elaborado pelo filósofo Jorge Larrosa para o campo da educação, mas dada a generalidade de suas categorias é possível estender sua aplicação a outros objetos. Conforme Larrosa:

[...] o que me proponho é sugerir uma perspectiva teórica, numa clave foucaultiana, para a análise das práticas pedagógicas que constroem e medeiam a relação do sujeito consigo mesmo: essa relação na qual se estabelece, se regula e se modifica a experiência que a pessoa tem de si mesma, a experiência de si (LARROSA, 2011, p. 37).

O alvo principal de Larrosa são aquelas atividades pedagógicas que solicitam dos estudantes um exame das próprias produções, seguido por uma autoavaliação. A aplicação do modelo permite enxergar cinco dimensões-etapas envolvidas em cada atividade e que repercutem sobre a experiência que o estudante tem de si mesmo. Segundo Larrosa:

[...] a experiência de si pode ser analisada como resultado do entrecruzamento, em um dispositivo pedagógico, de tecnologias óticas de autorreflexão, formas discursivas (basicamente narrativas) de autoexpressão, mecanismos jurídicos de autoavaliação, e ações práticas de autocontrole e autotransformação (LARROSA, 2011, p. 38).

Nessa citação são mencionadas, ainda que não explicitamente, as cinco dimensõesetapas previstas no modelo. São elas: ver-se, expressar-se, narrar-se, julgar-se e dominarse. Essas dimensões estão implicadas em atividades escolares que têm em vista a transformação de seus participantes. A expectativa desse tipo de atividade é fazer com que o estudante exponha seus trabalhos e suas ideias, reconheça-se nas ações e no percurso que vem trilhando, para, em seguida, julgá-lo. A meta mais imediata desse processo pode ser aprimorar uma habilidade específica, melhorar o desempenho em uma disciplina, por exemplo. A grande meta, por sua vez, é introduzir no estudante o espírito da autoanálise, é fazer com que ele se responsabilize pela própria performance na vida social.

Os parágrafos a seguir procuram delinear o conteúdo de cada uma das cinco dimensões. Em primeiro lugar, as atividades que visam a transformação dos indivíduos os convidam a olhar e ver suas produções, dar atenção, apreciar os detalhes. Esse gesto, sugere que o produtor se veja em sua produção e identifique-se com ela. Trata-se aí de uma pedagogia do olhar.

A segunda dimensão, "expressar-se", refere-se tanto ao ato de opinar, apresentar o próprio ponto de vista sobre um dado assunto, quanto falar sobre si mesmo, o que pensa e sente. Larrosa (2011) sugere problematizar essa ideia de autoexpressão lembrando que 
qualquer enunciado só adquire significado porque recorre a uma linguagem. A linguagem, no entanto, não presentifica seu referente, ela apenas representa-o, isto é, coloca-se em seu lugar. O referente e sua representação pela linguagem são duas coisas distintas. Sendo assim, quando um indivíduo "expressa-se", falando de si mesmo, ele na verdade está falando aquilo que sua linguagem Ihe permite falar. Essa dimensão serve, portanto, para pôr em xeque a linguagem em questão. Vale a nota de que "linguagem" não diz respeito apenas à língua, mas a todo meio de expressão relativamente codificado, como é o caso da linguagem fotográfica, vídeo/cinematográfica etc.

A terceira dimensão, "narrar-se", inclui o fator tempo e pede que o indivíduo observe sua trajetória, o conjunto de seus trabalhos, suas vivências, sua atuação. A história de cada um, porém, não é feita apenas daquilo que vivenciou diretamente, como anotou Larrosa neste trecho:

O que somos ou, melhor ainda, o sentido de quem somos, depende das histórias que contamos e das que contamos a nós mesmos. Em particular, das construções narrativas nas quais cada um de nós é, ao mesmo tempo, o autor, o narrador e o personagem principal. Por outro lado, essas histórias estão construídas em relação às histórias que escutamos, que lemos e que, de alguma maneira, nos dizem respeito na medida em que estamos compelidos a produzir nossa história em relação a elas. Por último, essas histórias pessoais que nos constituem estão produzidas e mediadas no interior de práticas sociais mais ou menos institucionalizadas (LARROSA, 2011, p. 48).

Se o ver-se, o expressar-se e o narrar-se estão mais ligados ao "mero" registro e objetivação do pensamento, a quarta dimensão, "julgar-se", solicita que cada um considere criticamente seu percurso, sua narrativa. Intervém nessa dinâmica, portanto, um elemento que está, de certa maneira, além ou fora da própria narrativa. Trata-se dos valores e critérios de julgamento. Esses deverão ser aplicados sobre a narrativa com a finalidade de averiguar seu grau de correção, legitimidade ou beleza. Um ponto-chave dessa dimensão é que os critérios não são "dados brutos", mas produções históricas.

A quinta dimensão, "dominar-se", é o corolário de todo o processo. Só se pode dominar um dado fenômeno na medida em que existe conhecimento sobre ele, na medida em que se pode separar suas partes, examiná-las e, a partir de critérios, qualificá-las. É isso que preveem as atividades pedagógicas que requisitam autoavaliação. Dominar-se significa objetivar a subjetividade, dar forma e estabilidade a algo que é a princípio informe e difuso. Esse processo permite ao indivíduo agir sobre si mesmo. Enfim:

Aprender a ver-se, a dizer-se, ou a julgar-se é aprender a fabricar o próprio duplo. E a 'sujeitar-se' a ele. Esse duplo está construído pela composição do eu que vejo quando me observo a mim mesmo, do eu que expresso 
quando me digo a mim mesmo, do eu que narro quando construo temporalmente minha própria identidade, do eu que julgo quando me aplico um critério, do eu que domino quando me governo (LARROSA, 2011, p. 80).

\section{PRODUÇÃO DE SUBJETIVIDADE NO INSTAGRAM}

De que maneira as imagens compartilhadas pelo Instagram contribuem para a intensificação da subjetividade e, dessa forma, atuam em consonância com o biopoder contemporâneo? Essa foi a questão de partida e a qual se deseja agora oferecer algumas respostas. Vale insistir no sentido dado aqui à expressão "intensificação de subjetividade": trata-se de um processo complexo pelo qual seres humanos são estimulados a dirigir a atenção sobre "si mesmos" e incorporar noções como individualidade, autoconsciência, liberdade e responsabilidade. A discussão se fundamenta no modelo apresentado no tópico anterior e segue a ordem das cinco dimensões-etapas.

Ver-se. Ao capturar imagens de si e de suas experiências, cada um está criando um registro visual de sua vida, um registro que ficará disponível ao próprio usuário e ao outro. Ao acumular essas imagens, os usuários educam seu olhar, aprendem a prestar atenção em detalhes de seus rostos e corpos, e dos rostos e corpos do outro. Aprendem também qual é o modo "certo" de aparecer nas imagens, que lugares são mais interessantes. Prestar atenção possibilita ver elementos que antes talvez não eram percebidos. Com o Instagram, colocar-se em evidência, ver-se e ver os amigos tornam-se atos rotineiros e momentos de reflexão sobre "si mesmo". Vive-se uma cultura da autoexposição, em que expor a própria vida tornou-se parte da rotina, naturalizou-se (SIBILIA, 2015).

Expressar-se. O Instagram permite ao usuário expressar-se por meio de imagem, texto e áudio. Os comentários a seguir, porém, dirigem-se especialmente à expressão visual. Expressar-se significa apresentar, mostrar a si mesmo. Em selfies é provável que usuários imaginem estar falando de si mesmos, expressando a si mesmos. Essa ideia, entretanto, pode ser problematizada. A crença de que a selfie expressa o que o indivíduo é desconsidera ou menospreza a atuação do instrumento que produz a imagem. A rigor, o que aparece não é apenas o usuário, e sim o usuário ao modo do dispositivo. Esse detalhe importa porque diferentes dispositivos podem criar diferentes representações de um mesmo objeto. O ponto interessante é que a participação do dispositivo tende a ser ignorada pelo usuário que assimila a imagem como sendo seu simples duplo. Expressarse implica necessariamente recorrer às formas disponíveis de expressão em um tempo e espaço específicos. Expressar-se no Instagram significa fazer uma selfie para dizer onde 
se está e o que se está sentindo, gravar um vídeo mostrando o local onde se está e o que se está fazendo, e com quem. Tais expressões, entretanto, não são exatamente "do próprio" usuário, e sim o resultado de uma composição com o Instagram. Importante: apesar de ser colocada para a dimensão do "expressar-se", essa ideia deve ser estendida para todo o tópico. Ao referir ou apenas refletir sobre "si mesmo", o humano sempre recorre a uma linguagem, a um conjunto de signos e instrumentos prévios e que possuem história. Portanto, não há objetividade ou neutralidade na expressão ou no pensamento "sobre si mesmo", há sempre composição com o recurso em uso.

Narrar-se. Ao considerar as imagens em uma ordem cronológica ou como constelação (isto é, sem uma sequência específica), o usuário tem uma ideia do percurso que vem trilhando, do que fez, do que já foi. Isso inclui sua aparência física, os objetos que possui, as pessoas com quem tem convivido, os locais frequentados. Um percurso que se converte em uma narrativa sobre o que esse usuário é. O Instagram age, assim, como um álbum fotográfico, com a diferença de que o antigo álbum analógico estava muito restrito em termos de alcance. Geralmente, só familiares e alguns amigos o acessavam (STURKEN, 2017). Ao permitir "escrever" histórias pessoais, o Instagram também pode ser aproximado, em alguns aspectos, ao antigo diário privado. Tanto em um como em outro, os escritores registram regularmente momentos de suas vidas, experiências pessoais, e expressam gostos, ideias e sentimentos. Em ambos, abre-se espaço para mudanças na experiência que o escritor tem de si. Por outro lado, existem grandes diferenças entre os antigos diários e a plataforma digital. A escrita no Instagram é muito mais visual que linguística e, geralmente, dirige-se a um público amplo, e não apenas o próprio remetente, como acontecia com os diários privados.

Ver-se, expressar-se, narrar-se, essas três etapas se referem ao registro da vida. Vida que se não fosse fotografada e videografada restaria apenas na memória dos que viveram. O registro visual permite que o usuário reflita sobre o que foi, reveja momentos, compare-os entre si e com os registros dos outros.

Julgar-se. As ações anteriores já continham alguma forma de juízo. Nesta etapa, entretanto, o que se considera é o conjunto de momentos visuais que, a seu modo, compõem uma narrativa. No Instagram, o julgamento é feito pelos próprios usuários, a partir dos instrumentos já disponibilizados pela plataforma, como as curtidas, os comentários e a quantidade de seguidores. Vale notar que o simples fato de tais instrumentos existirem constitui uma espécie de estímulo à avaliação do outro e, igualmente, ao acompanhamento da própria performance digital. Julgar-se é inserir um critério na relação entre o juiz e a 
própria narrativa. E o juízo tem sempre uma dimensão social, embora possa se manifestar na ação de um indivíduo específico. O juízo tem uma dimensão social porque os critérios utilizados são parte de sistemas de crenças e valores, que por sua vez são produções coletivas. No Instagram, cada usuário pode julgar as próprias narrativas e as narrativas do outro. Os critérios, entretanto, tendem a ser os mesmos ou tendem a se harmonizar. Isso pode ser inferido pelo modo como as imagens da plataforma se repetem, seja no aspecto formal, seja em termos de conteúdo. Conforme Sibilia (2015), os critérios utilizados em redes sociais (não só no Instagram) para avaliação da exposição não nascem nas próprias redes, eles dialogam e se inspiram na tradição fotográfica, no cinema, na mídia e na publicidade. Essas fontes oferecem subsídios para análise de elementos formais, ou "estéticos" em sentido largo, que podem ser compreendidos em termos de linguagem fotográfica.

Dominar-se. A partir da visibilidade de si e do outro, das narrativas que se depreendem das imagens e dos julgamentos realizados pela rede, o usuário está pronto para dominar-se, isto é, tomar posse de si mesmo e conduzir-se. Insiste-se que todos esses gestos autorreferenciais devem ser lidos, na verdade, como composições do indivíduo com o Instagram: dominar-se à maneira da plataforma, segundo os recursos que a plataforma disponibiliza.

O biopoder trabalha com a lógica do autogoverno, ou seja, não obriga seus subordinados de forma explícita, ele procura convencê-los. Estados, corporações e mídias sociais fornecem informações acerca das questões que interessam aos indivíduos, oferecem os critérios para realizar avaliações sobre as opções, os produtos e os serviços disponíveis, e então incentivam cada qual a fazer as "suas" escolhas e decida "por si só". O Instagram está em sintonia com essa lógica e engendra em seus usuários a sensação de agir por conta própria, ser dono da própria performance.

As imagens compartilhadas diariamente na plataforma fixam experiências de milhões de usuários, objetivam partes de suas vidas. Essas imagens revelam o que interessa para aquelas pessoas, e a rede gradativamente constrói concepções sobre o que é importante, o que é divertido, o que é desejável e invejável. Em paralelo, o Instagram oferece meios para que seus usuários analisem as postagens e façam seus julgamentos utilizando recursos como curtidas e comentários. Experiências pessoais fluidas e efêmeras tornam-se, assim, fatos estabilizados e avaliáveis.

$\mathrm{Na}$ escola, a subjetividade do estudante tende a ser alterada a partir da revisão de suas várias provas e trabalhos, como lembrou Larrosa (2011). Ao recuperar seus materiais 
com os apontamentos do professor, vê-los em perspectiva, compará-los com os resultados de colegas, o estudante forma uma ideia de seu percurso, conhece a "si mesmo", percebe o que está bom e o que pode ser melhorado. Guardadas as muitas diferenças entre o ambiente escolar e as redes sociais, é possível imaginar que algo parecido se desenrola na relação dos usuários com o Instagram. Certas imagens, certos conteúdos podem despertar no usuário movimentos comparativos e, a partir daí, gerar desejo, identidade, reconhecimento. São movimentos, portanto, que podem repercutir sobre a subjetividade do usuário e alterar a maneira como percebe a si mesmo e sua vida.

Preocupações como acompanhar a vida do outro e cultivar uma imagem cool (SHELDON; BRYANT, 2016) indicam que entre os usuários do Instagram tem-se desenvolvido um espírito de competitividade, uma competição pelo olhar e pela atenção do outro. Isso reforça uma ideia já bastante difundida de que a esfera pessoal ou privada foi contagiada pela mesma racionalidade que antes se restringia ao universo das empresas, uma racionalidade na qual disputas entre concorrentes e planejamento estratégico ocupam uma posição central (DARDOT; LAVAL, 2016).

Acredita-se, desse modo, que enquanto o usuário do Instagram supõe estar apenas divertindo-se, informando-se e consumindo bens e serviços, ele está também configurando seu jeito de pensar e agir em relação a si e aos outros.

\section{PROBLEMAS COM A LIBERDADE CONTEMPORÂNEA}

Esta seção explora um dos elementos centrais da subjetividade engendrada pelo biopoder e, como tem sido defendido aqui, por mídias sociais como o Instagram: a liberdade. Para pensadores como Han (2014), Rose (1998) e Pelbart (2007), a liberdade que hoje se propaga pode ser bastante enganadora e, inclusive, estar na raiz de uma série de doenças mentais (SAFATLE, 2012; HAN, 2015).

Sob certa ótica, é possível afirmar que os seres humanos de hoje são mais livres do que aqueles que viveram nas sociedades tradicionais e nas sociedades modernas (GIDDENS, 2002). Liberdade, nesse caso, significa deixar para trás normas e imperativos da tradição e das instituições, significa uma tendência a realizar escolhas e a tomar decisões de maneira mais individualizada no que tange à vida profissional, escolar, familiar, erótico-afetiva, espiritual etc. 
Nas sociedades da alta modernidade ou pós-modernas, a gradual desinstalação do aparato de Bem-Estar Social e o avanço das políticas neoliberais acompanham essa tendência, mas também adicionam novos contornos à noção de liberdade. Conforme Rose (2011), nessas sociedades, a escolha não é um "poder", mas antes um "dever" do cidadão. De forma paradoxal, o indivíduo pós-moderno é obrigado a ser livre, ele tem que escolher, tem que decidir e deve arcar com os custos de seu comportamento. "Desamarrado" da assistência do Estado, cada qual está livre para escolher os serviços que melhor atendem as suas condições e preferências. Além disso, esse indivíduo é crescentemente incentivado ao empreendedorismo. Ou seja, já não se trata apenas de escolher a profissão e a empresa em que se pretende atuar, e sim de inventar o próprio negócio. Por esse prisma, o ser humano teria, senão eliminado, pelo menos minimizado muito daquilo que sofria como coerção externa, isto é, coerção da tradição, da cultura, do Estado, da empresa moderna.

Apesar de bastante aceita, a ideia de que a liberdade tem sido ampliada pode ser problematizada. É o que faz Han (2014) ao sugerir que as formas de coerção não estão diminuindo e dando lugar à liberdade. A coerção está apenas mudando sua topologia, passando de "fora" para "dentro" do sujeito. Os limites e leis que antes vinham do outro passam a vir, em certo sentido, do próprio sujeito, e isso traz consequências importantes. Conforme Han:

Vivimos en una fase histórica especial en la que la libertad misma da lugar a coacciones. La libertad del poder hacer genera incluso más coacciones que el disciplinario deber. El deber tiene un límite. El poder hacer, por el contrario, no tiene ninguno. Es por ello que la coacción que proviene del poder hacer es ilimitada (HAN, 2014, p. 7).

Nessa provocativa passagem, Han (2014) afirma que a liberdade foi convertida em um tipo de coação pelo neoliberalismo. A chave para compreender essa ideia está na noção de limite. Antes, quando a coação era externa, havia um limite claro, sabia-se qual era a lei e quem a estabelecia. Sabia-se contra o que resistir: a Igreja, o Estado, a empresa. Livre seria aquele que se pusesse a enfrentar e conseguisse superar as forças daquelas instituições. Surge, entretanto, um novo problema. Nas sociedades pós-modernas, a coação se dá internamente. Aquele que estabelece as leis e aquele que as deve cumprir são a mesma pessoa. Na esfera do trabalho, o empreendedor ilustra essa situação, pois se apresenta como superior e subordinado ao mesmo tempo. É aí que liberdade e coação se confundem. $O$ antigo trabalhador tinha horário e local de trabalho explícitos; tinha também metas e prazo claros a cumprir. $O$ empreendedor não possui esses demarcadores, a menos que ele próprio os coloque. É precisamente neste ponto que a liberdade do sujeito 
pós-moderno se converte em coação, já que todos os passos da empresa estão em suspenso, à espera de suas decisões. O grande problema da condição atual, para Han (2014), é o conflito do sujeito com ele mesmo, porque para ser livre ele precisa enfrentar e vencer a si mesmo, ou, posto de forma trágica, eliminar a si mesmo.

Antes de comentar possíveis desdobramentos patológicos desse conflito individual, é preciso lembrar que esse modo de organização de ideias e comportamentos vai além do mundo do trabalho. A racionalidade que era típica e exclusiva do mundo dos negócios se espraiou e passa a estruturar toda a vida social. Conforme Dardot e Laval (2016, p. 327), o indivíduo engendrado na lógica neoliberal "[...] procura sobretudo trabalhar a si mesmo com o intuito de transformar-se continuamente, aprimorar-se, tornar-se sempre mais eficaz." 0 problema dessa lógica está na frequência e na intensidade com que a sensação de instabilidade e de risco se apresenta. Nas sociedades neoliberais, cada indivíduo precisa estar sempre pronto para criar saídas e se reinventar. Isso tem seus custos e implica sofrimento. Um sinal de alerta foi aceso nas últimas décadas com o avanço significativo das patologias mentais, como é o caso da depressão (HAN, 2015; SAFATLE, 2012). De forma simplificada, para a teoria social, a depressão está ligada a pelo menos três fatores que emergem ou se exacerbam nas sociedades pós-modernas.

O primeiro fator é a incitação à autorrealização, à felicidade e ao sucesso. Conforme Safatle (2005), a perspectiva lacaniana vai ainda mais longe e propõe que não se trata de estímulo, mas de obrigação de gozo. A sociedade contemporânea não apenas não reprime, mas obriga o indivíduo a gozar ao máximo. Para Sibilia (2015), essa nova injunção estaria relacionada com a preocupação dos usuários em cultivar um "eu" feliz, atraente e invejável nas redes sociais. O segundo fator está muito próximo ao primeiro, trata-se do recrudescimento do individualismo (HAN, 2015). Em vez de submissão a alguma ordem e repressão de particularidades, ganha força a ideia de que é preciso ser autônomo e autêntico, ser "você mesmo!". Individualização implica, de certa forma, liberdade já que predomina a vontade do indivíduo sobre a do grupo. Produz, por outro lado, fragmentação social e o sentido de responsabilidade. $O$ indivíduo agora deve escolher como conduzir a própria vida, mas precisa saber que agirá por conta própria e não haverá com quem compartilhar eventuais fracassos. Terceiro, nas sociedades pós-modernas a exigência de alto desempenho atingiu um novo patamar. Indivíduos e instituições estão nessa mesma condição, todos estão buscando maneiras de superar seus concorrentes. Não é difícil imaginar que tal movimento tende a gerar ainda mais competição e exigências de alto desempenho em um processo que leva ao esgotamento (HAN, 2015). 
O cenário pós-moderno talvez possa ser resumido da seguinte forma. Todas as amarras foram desfeitas, agora tudo é possível. Sendo assim, cada um pode e deve correr atrás do sucesso e da autorrealização. Mas, para ser um vencedor, é preciso muito trabalho, resiliência e superação dos próprios limites. Tudo isso em um contexto de grande concorrência e instabilidade. Aparentemente, a depressão, enquanto patologia do ânimo e recusa da ação, é uma das respostas a essas circunstâncias. Como disseram Dardot e Laval (2016, p. 356), “A depressão é [...] o outro lado do desempenho, uma resposta do sujeito à injunção de se realizar e ser responsável por si mesmo, de se superar cada vez mais na aventura empresarial." Han, por sua vez, acentua o caráter paradoxal da noção contemporânea de liberdade, dizendo o seguinte: "A lamúria do indivíduo depressivo de que nada é possível só se torna possível numa sociedade que crê que nada é impossível." (HAN, 2015, p. 29).

Há, ainda, um outro ponto que merece destaque nessa discussão a respeito das ideias de poder e liberdade. Trata-se de recolocar esses dois termos. Se liberdade significa autonomia que deriva do recuo dos poderes, então, de acordo com a ótica adotada aqui, o ser humano não está vivendo tempos de maior liberdade. Talvez, esteja havendo o contrário. Para Pelbart (2007) e Rose (1998), a vida estaria completamente monitorada e submetida aos poderes, incluindo aí o que há pouco se imaginava privado, íntimo, como o sexo, o sonho, o inconsciente e a fé.

Tudo isso soa demasiado ostensivo e talvez até irreal. É pouco intuitivo assumir que as "próprias" ideias e os "próprios" gostos são, na verdade, fruto de processos de governo. Mas, se prevalece a ideia de que os dias de hoje formam a época mais livre da história e que a ação do poder é mínima, então é porque o biopoder está cumprindo a contento a sua função, que é justamente fazer pensar e fazer agir como se tudo emanasse dos próprios indivíduos, de suas escolhas pessoais.

O poder está presente, mas não está do lado de "dentro" de cada um. A esquematização de Han (2014) segundo a qual o poder deixou o lado de "fora" e passou para "dentro" é antes um recurso didático para significar a guinada subjetiva do poder, não uma descrição realista. O poder que supostamente vem de dentro, sob a forma de autocobrança e autodeterminação, não nasce no sujeito. Esse poder é expressão da cultura e das relações sociais, inclusive aquelas que se materializam nos ambientes digitais, como é o caso do Instagram. O lado de dentro, então, não é autoconstituído nem autônomo, ele é produto de complexos encontros e composições com tudo aquilo que o cerca. Desse 
modo, o poder externo não diminuiu e tampouco deixou de existir, ele apenas se reconfigurou (ROSE, 2011).

\section{CONSIDERAÇÕES FINAIS}

O fato de o poder estar em toda a vida em sociedade não significa necessariamente um problema. Na contramão da tradição, Foucault (2006) concebeu o poder não como um mal em si. Lembrou que entre os amantes há relações de poder. Entre professor e aluno há relações de poder, e em ambos os casos essas relações podem ser positivas e produtivas. O que deveria ser enfrentado não era o poder, mas aquilo que Foucault (1995) chamou de escravidão, isto é, a dominação pura e simples do outro, a relação saturada de determinações.

Na perspectiva foucaultiana assumida aqui, poder não é o oposto e não exclui a liberdade. O exercício do poder pressupõe a liberdade, pressupõe que as regras estabelecidas e a relação entre os agentes possam ser outras e possam, no limite, ser rompidas. As ações de resistência estão contidas nas possibilidades de exercício do poder e, por isso mesmo, o poder precisa ser inteligente e flexível se quiser manter sua posição, reinventando-se frequentemente.

Esse é precisamente o ponto que interessa, porque para alterar as regras ou romper a ordem vigente, para que a resistência apareça é preciso que os sujeitos se deem conta das formas pelas quais estão sendo subjetivados. Não se pode resistir àquilo que não se vê e àquilo que não se conhece.

Quando se analisa o Instagram, é possível falar de relações de poder entre os usuários e entre cada usuário e a plataforma. Assim, valeria perguntar se os usuários estão cientes dos processos de subjetivação dos quais participam ao utilizar a rede. Estarão eles cientes dos potenciais efeitos que as imagens, os seus olhares, as suas curtidas e comentários têm sobre o outro? Inversamente, estarão cientes dos potenciais efeitos sobre si mesmos que têm as próprias imagens, mas também as imagens do outro, seus olhares, curtidas e comentários?

O problema não está tanto na utilização das mídias sociais, mas no desconhecimento de que nelas se engendram formas de se relacionar com o mundo, com os outros e consigo mesmo. O problema maior está na crença de que as ações que se realizam no Instagram e noutras mídias sociais são gestos de pura autonomia e autoexpressão. 


\section{REFERÊNCIAS}

ASLAM, Salman. Instagram by the numbers: stats, demographics \& fun facts, Omnicore, 26 jan. 2020. Disponível em: <https://www.omnicoreagency.com/instagram-statistics>. Acesso em: 30 jan. 2020.

DARDOT, Pierre; LAVAL, Christian. A nova razão do mundo: ensaio sobre a sociedade neoliberal. São Paulo: Boitempo, 2016.

FOUCAULT, Michel. O sujeito e o poder. In: DREYFUS, Hubert L.; RABINOW, Paul. Michel Foucault, uma trajetória filosófica: para além do estruturalismo e da hermenêutica. Rio de Janeiro: Forense Universitária, 1995. p. 321-249.

Ética, sexualidade, política (Ditos e Escritos, v. 5). 2. ed. Rio de Janeiro: Forense Universitária. 2006.

História da sexualidade: a vontade de saber 1. Rio de Janeiro: Graal, 2011.

GIDDENS, Anthony. Modernidade e identidade. Rio de Janeiro: Jorge Zahar Editor, 2002.

HAN, Byung-Chul. Psicopolítica: neoliberalismo y nuevas técnicas de poder. Barcelona: Herder, 2014.

Sociedade do cansaço. Petrópolis: Vozes, 2015.

HU, Yuheng; MANIKONDA, Lydia; KAMBHAMPATI, Subbarao. What we instagram: a first analysis of instagram photo content and user types. In: Proceedings of the 8th International Conference on Weblogs and Social Media, ICWSM 2014. Ann Arbor: The AAAI Press, 2014. p. 595-598. Disponível em: <https://www.aaai.org/ocs/index.php/ ICWSM/ICWSM14/paper/viewFile/8118/8087>. Acesso em: 21 fev. 2020. 
INSTAGRAM Statistics. Instagram info center, 2019. Disponível em: <https://instagrampress.com/our-story/>. Acesso em: 5 jan. 2019.

LARROSA, Jorge. Tecnologias do Eu e educação. In: SILVA, Tomaz Tadeu da (Org.). 0 sujeito da educação: estudos foucaultianos. 7. ed. Petrópolis: Vozes, 2011. p. 35-86.

LASÉN, Amparo; PUENTE, Héctor. La cultura digital. Tecnologías Sociales de la Comunicación. Barcelona: UOC, 2016, p. 1-45. Disponível em: <https://www.academia.edu/27037780/La_cultura_digital>. Acesso em: 14 nov. 2019.

MANOVICH, Lev. Subjects and styles in Instagram photography (part 1), 2016.

Manovich.net. Disponível em: <http://manovich.net/index.php/projects/subjects-andstyles-in-instagram-photography-part-1>. Acesso em: 14 ago. 2019.

PELBART, Peter Pál. Biopolítica. Sala Preta, São Paulo, v. 7, p. 57-66, 2007. Disponível em: <http://www.revistas.usp.br/salapreta/article/view/57320/60302>. Acesso em: 10 ago. 2019.

ROSE, Nikolas. Governando a alma: a formação do eu privado. In: SILVA, Tomaz Tadeu da (Org.). Liberdades reguladas: a pedagogia construtivista e outras formas de governo do eu. Petrópolis: Vozes, 1998. p. 30-45.

Inventando nossos selfs: psicologia, poder e subjetividade. Petrópolis: Vozes, 2011.

SAFATLE, Vladimir. Depois da culpabilidade: figuras do supereu na sociedade de consumo. In: DUNKER, Christian; PRADO, José Luiz Aidar (Orgs.). Zizek crítico: política e psicanálise na era do multiculturalismo. São Paulo: Hacker Editores, 2005. p. 119-140.

Perto demais da redenção: depressão, flexibilidade e fim da ética do trabalho, 2012. Artepensamento: ensaio filosóficos e políticos. Disponível em: <https://artepensamento.com.br/item/perto-demais-da-redencao-depressao-flexibilidadee-fim-da-etica-do-trabalho/?_sf_s=safatle >. Acesso em: 12 dez. 2019. 
SHELDON, Pavica; BRYANT, Katherine. Instagram: motives for its use and relationship to narcissism and contextual age. Computers in Human Behavior, v. 58, p. 89-97, maio 2016. Disponível em: <https://doi.org/10.1016/j.chb.2015.12.059>. Acesso em: 7 dez. 2019.

SIBILIA, Paula. O universo doméstico na era da extimidade: nas artes, nas mídias e na internet. Eco Pós, Rio de Janeiro, v. 18, n. 1, p. 133-147, 2015. Disponível em: <https://revistas.ufrj.br/index.php/eco_pos/article/view/2025>. Acesso em: 12 ago. 2019.

STURKEN, Marita. Da Kodak e Polaroid ao Google e ao Facebook: fotografias de família e fotografias do eu. Revista de Comunicação e Linguagens, Lisboa, n. 47, p. 8-24, out./prim. 2017. Disponível em:

<http://www.fcsh.unl.pt/rcl/index.php/rcl/issue/view/3/showToc>. Acesso em: 5 out. 2019.

\section{NOTAS}

\section{Fabíola Stolf Brzozowski}

Doutora em Saúde Coletiva pela Universidade Federal de Santa Catarina, Florianópolis, Brasil fabiola.stolf@gmail.com https://orcid.org/0000-0002-8697-2120

\section{Mauricio José Melim}

Doutorando do Programa Interdisciplinar em Ciências Humanas da Universidade Federal de Santa Catarina, Florianópolis, SC, Brasil

Mestre em Ciências da Comunicação pela Faculdade lelusc, Joinville, Brasil

mauriciomelim@gmail.com

http://orcid.org/0000-0002-1111-1625

\section{Endereço de correspondência do principal autor}

Rua Eugênio Fleischer, 8, ap. 401, 89.218-480, Joinville, SC, Brasil

\section{AGRADECIMENTOS}

Gostaríamos de registrar nossos agradecimentos aos estudantes de graduação de Jornalismo Arthur Lincoln Ferreira e de Publicidade e Propaganda Eduardo de Matos Fernandes Rodrigues e Henrique Fernandes Dias, da Faculdade lelusc, por participarem das discussões que deram origem a este trabalho.

\section{CONTRIBUIÇÃO DE AUTORIA}

Concepção e elaboração do manuscrito: M. J. Melim, F. S. Brzozowski

Investigação: M. J. Melim, F. S. Brzozowski

Discussão dos resultados: M. J. Melim, F. S. Brzozowski

Supervisão: F. S. Brzozowski

Revisão e aprovação: F. S. Brzozowski 
CONJUNTO DE DADOS DE PESQUISA

Todo o conjunto de dados que dá suporte aos resultados deste estudo foi publicado no próprio artigo.

\section{FINANCIAMENTO}

O presente trabalho foi realizado com apoio da Coordenação de Aperfeiçoamento de Pessoal de Nível Superior - Brasil (CAPES) - Código de Financiamento 001

\section{CONSENTIMENTO DE USO DE IMAGEM}

Não se aplica.

\section{APROVAÇÃO DE COMITÊ DE ÉTICA EM PESQUISA}

Não se aplica.

\section{CONFLITO DE INTERESSES}

Não se aplica.

\section{LICENÇA DE USO}

Os autores cedem à Revista Internacional Interdisciplinar INTERthesis os direitos exclusivos de primeira publicação, com o trabalho simultaneamente licenciado sob a Licença Creative Commons Attribution (CC BY) 4.0 International. Esta licença permite que terceiros remixem, adaptem e criem a partir do trabalho publicado, atribuindo o devido crédito de autoria e publicação inicial neste periódico. Os autores têm autorização para assumir contratos adicionais separadamente, para distribuição não exclusiva da versão do trabalho publicada neste periódico (ex.: publicar em repositório institucional, em site pessoal, publicar uma tradução, ou como capítulo de livro), com reconhecimento de autoria e publicação inicial neste periódico.

\section{PUBLISHER}

Universidade Federal de Santa Catarina. Programa de Pós-graduação Interdisciplinar em Ciências Humanas. Publicação no Portal de Periódicos UFSC. As ideias expressadas neste artigo são de responsabilidade de seus autores, não representando, necessariamente, a opinião dos editores ou da universidade.

\section{EDITORES}

Javier Ignacio Vernal e Silmara Cimbalista.

\section{HISTÓRICO}

Recebido em: 15-01-2020 - Aprovado em: 26-02-2021 - Publicado em: 05-03-2021 